\title{
Protective effect of icariin on kidney in 5/6 nephrectomized rats and its mechanism
}

\author{
S.R. Liang' ${ }^{1}$ J.W. Bi ${ }^{2}$, Z.L. Guo ${ }^{1}$, Y. Bai ${ }^{1}$ and Z. $\mathrm{Hu}^{3}$ \\ ${ }^{1}$ Department of Nephrology, \\ The First Affiliated Hospital of Henan University of Science and Technology, \\ Luoyang, Henan Province, China \\ ${ }^{2}$ Department of Respiratory and Critical Care Medicine, \\ The First Affiliated Hospital of Henan University of Science and Technology, \\ Luoyang, Henan Province, China \\ ${ }^{3}$ Department of Nephrology, Qilu Hospital of Shandong University, \\ Jinan, Shandong Province, China \\ Corresponding author: S.R. Liang \\ E-mail: surenliangcn@163.com
}

Genet. Mol. Res. 13 (3): 6466-6471 (2014)

Received July 11, 2013

Accepted January 16, 2014

Published August 25, 2014

DOI http://dx.doi.org/10.4238/2014.August.25.10

\begin{abstract}
The aim of this study was to investigate the renal protective effect of icariin in 5/6 nephrectomized rats and the molecular mechanisms involved. Forty male Sprague-Dawley rats were randomly divided into 5 groups: sham-operated group, 5/6 nephrectomy model group, icariin groups (20 and $40 \mathrm{mg} / \mathrm{kg}$ ), and benazepril group. After 12-weeks treatment, 24-h urine and serum were collected, and urine protein, serum creatinine, and blood urea nitrogen were determined. The rats were then sacrificed and fresh kidney tissues were prepared to obtain single cell suspensions. Cell cycle distribution and cell apoptosis were determined by annexin V-FITC/propidium iodide (PI) double staining using a flow cytometer. mRNA expression of Bcl-2 and Bax was examined using quantitative real-time PCR. After 12-weeks treatment, urinary protein, serum creatinine, and blood urea nitrogen in the icariin-treated group were much lower than in the untreated group
\end{abstract}


compared with 5/6 nephrectomy model. Icariin reduced the percentage of S phase cells, increased the percentage of G0/M phase cells, and inhibited apoptosis in the renal cells. mRNA expression of Bcl-2 and Bax was decreased. In conclusion, icariin has a renal protective effect in 5/6 nephrectomized rats, which may be related mainly to alterations in cell cycle distribution and expression of apoptotic genes.

Key words: Nephrectomy; Icariin; Apoptosis; Apoptotic genes

\section{INTRODUCTION}

Epimedium is the dried aboveground part of Epimedium brevicornum Maxim. Epimedium is pungent and sugary, and it is used for liver and kidney ailments, to strengthen bones and muscles and to protect against rheumatism (National Pharmacopoeia Committee, 2005). As a traditional Chinese medicine, Epimedium is widely used for the treatment of osteoporosis (Peng et al., 2009), impotence (Ho and Tan, 2011), and diabetic nephropathy (Zhang et al., 2012) in clinics. Modern research has shown that icariin is a major active component isolated from Epimedium (Xie et al., 2007). In this study, we investigated the renal protective effect of icariin in $5 / 6$ nephrectomy rats and its possible mechanisms by examining cell apoptosis and the expression of the apoptotic genes Bcl-2 and Bax in the 5/6 nephrectomy model.

\section{MATERIAL AND METHODS}

\section{Animals}

Male Sprague-Dawley (SD) rats (200 to $220 \mathrm{~g}$ body weight) were purchased from the experimental animal center of Henan Province [Permit number: SCXK (yu) 2005-0001]. This study was carried out in strict accordance with the recommendations in the Guide for the Care and Use of Laboratory Animals of the National Institutes of Health. The animal use protocol was reviewed and approved by the Institutional Animal Care and Use Committee (IACUC) of the First Affiliated Hospital of Henan University of Science and Technology.

\section{Experimental design and tissue processing}

Forty SD rats were randomly divided into the sham-operated group $(\mathrm{N}=8)$ and $5 / 6$ nephrectomy model group $(\mathrm{N}=32)$. Subtotal $(5 / 6)$ nephrectomy was induced by two-step resection. Briefly, all operations were carried out under chloral hydrate anesthesia $(300 \mathrm{mg} / \mathrm{kg})$. The left kidney was exposed by blunt separation after laparotomy, carefully peeling around kidney tissues, and the upper and lower thirds of the kidney were ligated and excised, bleeding was controlled by compression. Four days later, a right flank incision was made, with the same anesthesia and laparotomy, exposing the right kidney. The renal pedicle was ligated and the right kidney was excised. In all, $5 / 6$ of kidney was excised after the two step operation. The sham-operated group rats were subjected to the same operation, but without excision of the kidney. Animals were allowed to recover, and the treatment was started after one week. The model group rats were then divided into 4 groups ( 8 rats each): the icariin-treated animals were 
gavaged with 20 or $40 \mathrm{mg} / \mathrm{kg}$ icariin (China Drugs and Biological Products Inspection Institute, China) daily. The benazepril group received $10 \mathrm{mg} / \mathrm{kg}$ oral benazepril (Novartis Pharma Schweiz AG, Switzerland) daily. The control group and sham-operated group were given the same dose of physiological saline. On week 12, the animals were killed and blood and tissues were collected.

\section{Determination of serum creatinine and blood urea nitrogen}

The urine in the metabolism cage was collected $24 \mathrm{~h}$ before sacrificing, and urinary protein was determined. Blood sampling was via the orbital venous plexus, and serum was obtained by centrifugation at $4000 \mathrm{rpm}$ for $10 \mathrm{~min}$. Serum creatinine and blood urea nitrogen were determined using an automatic biochemical analyzer. The capsule and medulla were removed from the kidneys, and the cleaned-up kidneys were stored at $-70^{\circ} \mathrm{C}$ for later flow cytometry and real-time PCR assays.

\section{Flow cytometric analysis of apoptosis and cell cycle}

Apoptosis and cell cycle distribution were evaluated by the method previously reported by Wang et al. (2011) with slight modification. Renal cortical tissues were prepared to provide single-cell suspensions before flow cytometry (FACS Calibur, BD, San Jose, CA, USA). The fresh renal tissues were cut and macerated followed by filtering through a 200-mesh filter paper, to give a single-cell suspension. The cell suspension was centrifuged at $800 \mathrm{~g}$, and the cells were washed once with PBS. The supernatant was discarded and the cells were fixed in $75 \%$ ethanol at $-20^{\circ} \mathrm{C}$ for $24 \mathrm{~h}$. Cells were concentrated to $1 \times 10^{5} / \mathrm{mL}$ and then stained with propidium iodide (PI) followed by cell cycle and apoptotic analysis using flow cytometry. All experiments were performed on an aseptic clean bench, and all instruments were sterilized with $75 \%$ alcohol before and after use.

\section{Total RNA extraction and real-time quantitative RT-PCR}

Total RNA was isolated from the fresh renal tissues using the Trizol reagent (Invitrogen, Carlsbad, CA, USA) according to manufacturer instructions. Reverse transcription was performed using a reverse transcription kit (Promega, Madison, WI, USA) and semi-quantitative PCR was performed by semi-quantitative RT-PCR (Takara, Ohtsu, Japan) to determine the mRNA levels of Bcl-2 and Bax. Sequences of primers for amplification of the bcl-2 gene were as follows: forward primer: 5'-CATGTGTGTGGAGAGCGTCAA-3'; reverse primer: 5'-GCCGGTTCAGGTACTCAGTCA-3'. The bax primers were as follows: forward primer: 5'-GGGGACGAACTGGACAGTAACAT-3'; reverse primer: 5'-GGAGTCTCACCCAACCA CCCT-3'. The $\beta$-actin primers were as follows: forward primer: 5'-TGTGCCCATCTACGAG GGGTATGC-3'; reverse primer: 5'-GGTACATGGTGGTGCCGCCAGACA-3'. Primers were purchased from Sangon (Shanghai, China). The relative abundances of Bcl-2 and Bax genes were estimated by the comparative quantification method $\left(2^{-\Delta \Delta C t}\right)$ with $\beta$-actin as the reference gene.

\section{Statistical analysis}

The SPSS 13.0 software (SPSS Inc, Chicago, IL, USA) was performed for statistical analysis. Data are reported as the means \pm SD. Drug effect was analyzed by the ANOVA 
method, in which comparison between groups was performed using the Dunnett $t$-test. $\mathrm{P}<$ 0.05 was considered to be statistically significant.

\section{RESULTS}

\section{Renal protective effect of icariin in 5/6 nephrectomized rats}

Urinary protein, serum creatinine and blood urea nitrogen were significantly increased $(\mathrm{P}<0.001)$ in the model group rats compared with sham-operated group rats, implying impaired renal function (Table 1). Urinary protein, serum creatinine, and blood urea nitrogen in the icariin-treated group rats significantly decreased compared with the model group (20 $\mathrm{mg} /$ kg group: $\mathrm{P}<0.05, \mathrm{P}<0.01, \mathrm{P}<0.05 ; 40 \mathrm{mg} / \mathrm{kg}$ group: $\mathrm{P}<0.01, \mathrm{P}<0.001, \mathrm{P}<0.01)$.

Table 1. Effect of icariin on renal function in $5 / 6$ nephrectomized rats $(\mathrm{N}=8)$.

\begin{tabular}{lcccc}
\hline Groups & Concentration $(\mathrm{mg} / \mathrm{kg})$ & Urinary protein $(\mathrm{mg} / 24 \mathrm{~h})$ & Serum creatinine $(\mu \mathrm{M})$ & Blood urea nitrogen $(\mathrm{mM})$ \\
\hline Sham-operated group & - & $24.9 \pm 6.7$ & $73.8 \pm 11.3$ & $4.15 \pm 1.28$ \\
5/6 nephrectomize group & - & $92.4 \pm 17.8^{* * *}$ & $166.5 \pm 24.2^{* * *}$ & $12.73 \pm 3.54^{* * *}$ \\
Icariin group & 20 & $77.5 \pm 21.4^{+}$ & $132.7 \pm 25.4^{++}$ & $9.09 \pm 2.17^{+}$ \\
Icariin group & 40 & $58.2 \pm 15.6^{++}$ & $103.8 \pm 21.1^{++}$ & $8.52 \pm 2.08^{++}$ \\
Benazepril group & 10 & $53.1 \pm 14.3^{++}$ & $94.9 \pm 18.5^{++}$ & $7.40 \pm 2.35^{++}$ \\
\hline
\end{tabular}

${ }^{* * *} \mathrm{P}<0.001$, compared with sham-operated group; ${ }^{+} \mathrm{P}<0.05,{ }^{++} \mathrm{P}<0.01,{ }^{+++} \mathrm{P}<0.001$, compared with $5 / 6$ nephrectomize group.

\section{Effects of icariin on apoptosis and cell cycle distribution of renal cells in 5/6 nephrectomy rats}

As shown in Table 2, 5/6 nephrectomy markedly altered the cell cycle distribution of renal cells. The percentage of $\mathrm{G} 0 / \mathrm{G} 1$ phase cells was significantly reduced $(\mathrm{P}<0.01)$, while the $\mathrm{S}$ phase cells were increased $(\mathrm{P}<0.001)$, and the apoptotic rate significantly increased ( $\mathrm{P}$ $<0.001)$. Treatment of $5 / 6$ nephrectomized rats with icariin did not influence the percentage of $\mathrm{G} 0 / \mathrm{G} 1$ phase renal cells, but a decreased $\mathrm{S}$ phase population $(\mathrm{P}<0.01$ for $20 \mathrm{mg} / \mathrm{kg}$ group; $\mathrm{P}<0.05$ for $40 \mathrm{mg} / \mathrm{kg}$ group) and increased $\mathrm{G} 2 / \mathrm{M}$ phase fraction $(\mathrm{P}<0.05$ for $20 \mathrm{mg} / \mathrm{kg} ; \mathrm{P}<$ 0.05 for $40 \mathrm{mg} / \mathrm{kg}$ ) were found. Also, the apoptotic cells were significantly fewer ( $\mathrm{P}<0.05$ for $20 \mathrm{mg} / \mathrm{kg} ; \mathrm{P}<0.01$ for $40 \mathrm{mg} / \mathrm{kg}$ ).

Table 2. Effect of icariin on cell apoptosis in 5/6 nephrectomized rats $(\mathrm{N}=8)$.

\begin{tabular}{lccccc}
\hline Groups & Concentration $(\mathrm{mg} / \mathrm{kg})$ & $\mathrm{G} 0 / \mathrm{G} 1$ & $\mathrm{~S}$ & $\mathrm{G} 2+\mathrm{M}$ & Apoptosis rate \\
\hline Sham-operated group & - & $71.5 \pm 9.86$ & $11.4 \pm 3.33$ & $17.1 \pm 3.65$ & $1.74 \pm 0.38$ \\
5/6 nephrectomize group & - & $46.8 \pm 8.74^{* *}$ & $32.9 \pm 6.48^{* * *}$ & $20.3 \pm 3.88$ & $9.52 \pm 1.85^{* * *}$ \\
Icariin group & 20 & $54.7 \pm 9.29$ & $18.5 \pm 4.16^{++}$ & $26.8 \pm 5.44^{+}$ & $7.65 \pm 1.49^{+}$ \\
Icariin group & 40 & $52.1 \pm 8.83$ & $22.4 \pm 6.79^{+}$ & $25.5 \pm 4.87^{+}$ & $6.41 \pm 1.28^{++}$ \\
Benazepril group & 10 & $63.8 \pm 9.43^{++}$ & $21.6 \pm 5.54^{++}$ & $14.6 \pm 2.69^{+}$ & $4.33 \pm 1.07^{+++}$ \\
\hline
\end{tabular}

**P $<0.01, * * * \mathrm{P}<0.001$, compared with sham-operated group; ${ }^{+} \mathrm{P}<0.05,{ }^{++} \mathrm{P}<0.01,{ }^{+++} \mathrm{P}<0.001$, compared with $5 / 6$ nephrectomize group.

\section{Icariin reduced the expression of Bcl-2 and Bax in 5/6 nephrectomy rats}

As shown in Figure 1, mRNA expression of Bcl-2 and Bax was significantly increased 
in the $5 / 6$ nephrectomized group compared with sham-operated group $(\mathrm{P}<0.001)$. Icariin at the concentration of $40 \mathrm{mg} / \mathrm{kg}$ significantly reduced mRNA expression of Bcl-2 and $\mathrm{Bax}(\mathrm{P}<$ $0.01)$, and in $20 \mathrm{mg} / \mathrm{kg}$ group rats, mRNA expression of Bax also reduced $(\mathrm{P}<0.05)$.

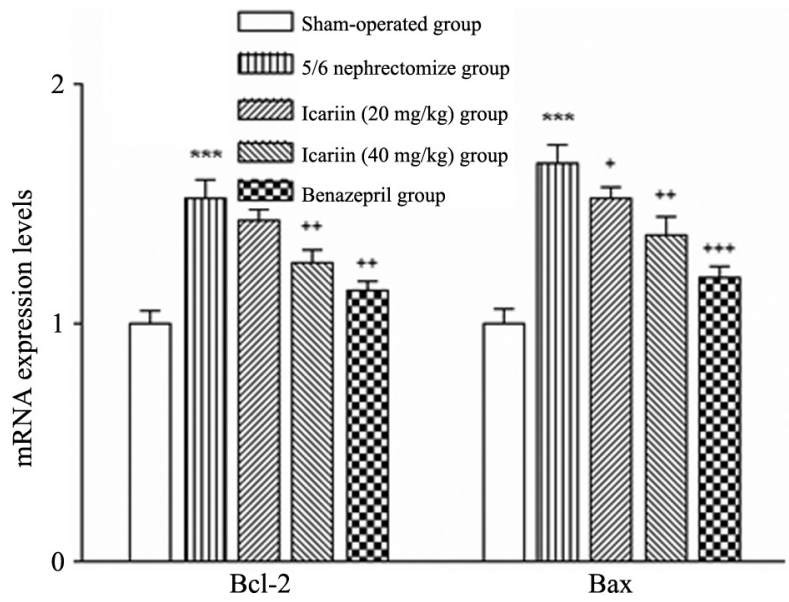

Figure 1. Icariin ruduced the expression of bcl-2 and bax in $5 / 6$ nephrectomy rats. ${ }^{* * *} \mathrm{P}<0.001$, compared with sham-operated group; ${ }^{+} \mathrm{P}<0.05,{ }^{++} \mathrm{P}<0.01,{ }^{++} \mathrm{P}<0.001$, compared with $5 / 6$ nephrectomize group.

\section{DISCUSSION}

Icariin is thought to be the principal active component of epimedium, and has many pharmacological activities such as renal protection and anti-aging (Qi et al., 2011; Liang et al., 2012). In this study, we found that icariin reduced serum creatinine, urea nitrogen, and 24-h urinary protein in the $5 / 6$ nephrectomized rats, indicating that icariin possesses a notable renal repair effect in incomplete kidney.

Apoptosis is involved in the progress of kidney diseases. Various kidney diseases are accompanied by apoptosis of renal cells (Sugiyama et al., 1996; Kitamura et al., 1998). Apoptosis is a biological process strictly regulated by multiple genes such as those of the bcl-2 family, which play a key role in apoptosis regulation. Bcl-2 is one of the most important anti-apoptotic genes, and can inhibit cell apoptosis and permit survival; Bax can inhibit the anti-apoptotic effects of Bcl-2 and induce cell apoptosis by forming a dimeric complex with Bcl-2 (Steller, 1995). Numerous studies have demonstrated that there is abnormal expression of Bax and Bcl-2 in diabetic nephropathy or 5/6 nephrectomy model rats (Huang et al., 2009; Kim et al., 2009, 2011; Zhao et al., 2012), suggesting that the alteration of Bax and Bcl-2 expression can influence apoptosis, and thereby affect the development of kidney diseases (Cui et al., 2011; He et al., 2011; Liao et al., 2012). In this study, we found that icariin can reduce mRNA expression of $\mathrm{Bcl}-2$ and Bax, showing that icariin can improve renal activity by regulating the expression of apoptosis-related factors. Cell apoptosis is closely related to the disruption of the cell cycle. The cell cycle consists of several phases, where DNA is doubled in S phase, and mitosis is initiated and completed in $\mathrm{G} 2 / \mathrm{M}$ phase. In this study, we found that icariin can reduce the percentage of $\mathrm{S}$ phase cells, and increase the number of G2/M phase cells, indicating that icariin can promote mitosis and proliferation in the incomplete kidney and decrease cell apoptosis. 
In conclusion, this study found that icariin possesses a renal repair effect in $5 / 6$ nephrectomized rats, and can inhibit apoptosis in kidney cells. These effects may be related to the inhibition of apoptosis-related genes such as Bcl-2 and Bax, and the alteration of cell cycle distribution.

\section{REFERENCES}

Cui WY, Tian AY and Bai T (2011). Protective effects of propofol on endotoxemia-induced acute kidney injury in rats. Clin. Exp. Pharmacol. Physiol. 38: 747-754.

He B, Zhang YT, Yuan XG, Sun JS, et al. (2011). Protective effects of Radix codonopsis on ischemia-reperfusion injury in rats after kidney transplantation. Pediatr. Surg. Int. 27: 1203-1212.

Ho CC and Tan HM (2011). Rise of herbal and traditional medicine in erectile dysfunction management. Curr. Urol. Rep. 12: $470-478$.

Huang J, Lee P, Mikami Y and Melamed J (2009). Dysplastic ("in-situ") lesions in multofocal renal oncocytomas (oncocytosis). Int. J. Clin. Exp. Pathol. 2: 583-587.

Kim YJ, Kim YA and Yokozawa T (2009). Protection against oxidative stress, inflammation, and apoptosis of highglucose-exposed proximal tubular epithelial cells by astaxanthin. J. Agric. Food Chem. 57: 8793-8797.

Kim YJ, Kim YA and Yokozawa T (2011). Pycnogenol modulates apoptosis by suppressing oxidative stress and inflammation in high glucose-treated renal tubular cells. Food Chem. Toxicol. 49: 2196-2201.

Kitamura H, Shimizu A, Masuda Y, Ishizaki M, et al. (1998). Apoptosis in glomerular endothelial cells during the development of glomerulosclerosis in the remnant-kidney model. Exp. Nephrol. 6: 328-336.

Liang Q, Wei G, Chen J, Wang Y, et al. (2012). Variation of medicinal components in a unique geographical accession of horny goat weed Epimedium sagittatum Maxim. (Berberidaceae). Molecules 17: 13345-13356.

Liao XH, Chen GT, Li Y, Zhang L, et al. (2012). Augmenter of liver regeneration attenuates tubular cell apoptosis in acute kidney injury in rats: the possible mechanisms. Ren Fail. 34: 590-599.

National Pharmacopoeia Committee (2005). Chinese Pharmacopoeia. 2005 Edition. Chemical Industry Press. Beijing.

Peng S, Zhang G, He Y, Wang X, et al. (2009). Epimedium-derived flavonoids promote osteoblastogenesis and suppress adipogenesis in bone marrow stromal cells while exerting an anabolic effect on osteoporotic bone. Bone 45: 534-544.

Qi MY, Kai C, Liu HR, Su YH, et al. (2011). Protective effect of icariin on the early stage of experimental diabetic nephropathy induced by streptozotocin via modulating transforming growth factor beta1 and type IV collagen expression in rats. J. Ethnopharmacol. 138: 731-736.

Steller H (1995). Mechanisms and genes of cellular suicide. Science 267: 1445-1449.

Sugiyama H, Kashihara N, Makino H, Yamasaki Y, et al. (1996). Apoptosis in glomerular sclerosis. Kidney Int. 49: 103111.

Wang Q, Hao J, Pu J, Zhao L, et al. (2011). Icariin induces apoptosis in mouse MLTC-10 Leydig tumor cells through activation of the mitochondrial pathway and downregulation of the expression of piwil4. Int. J. Oncol. 39: 973-980.

Xie J, Sun W, Duan K and Zhang Y (2007). Chemical constituents of roots of Epimedium wushanense and evaluation of their biological activities. Nat. Prod. Res. 21: 600-605.

Zhang J, Wang YB, Ma CG, Liu T, et al. (2012). Icarisid II, a PDE5 inhibitor from Epimedium wanshanense, increases cellular cGMP by enhancing NOS in diabetic ED rats corpus cavernosum tissue. Andrologia 44 (Suppl 1): 87-93.

Zhao G, Tu L, Li X, Yang S, et al. (2012). Delivery of AAV2-CYP2J2 protects remnant kidney in the 5/6-nephrectomized rat via inhibition of apoptosis and fibrosis. Hum. Gene Ther. 23: 688-699. 